\title{
Atopy, bronchial hyperresponsiveness, and peak flow variability in children with mild occasional wheezing
}

Hector Roizin, Avner Reshef, Ido Katz, Shlomo Benzaray, Michael Lison, Robert J Shiner
Department of Clinical Respiratory Physiology

H Roizin

I Katz

S Benzaray

R J Shiner

Department of Allergy and Clinical

Immunology

A Reshef

Community Paediatric Clinic, Or-Yehuda $M$ Lison

Chaim Sheba Medical Center and Tel Aviv University Medical

School, Tel-Hashomer 52621, Israel

Correspondence to: Dr R J Shiner.

Received 12 September

1994
Returned to authors

Returned to auth

20 January 1995

20 July 1995

20 July 1995

12 October 1995

\begin{abstract}
Background - Children who suffer from recurrent wheezy episodes are often promptly classified as asthmatic. The aim of this study was to evaluate a population of mild wheezy children with repeatedly normal spirometric tests at rest for atopy, bronchial hyperresponsiveness, and peak expiratory flow variability.
\end{abstract}

Methods - Thirty nine children aged 6-16 years with 1-12 wheezy attacks during the previous year were recruited from a community paediatric primary health care clinic serving an urban Israeli population. The conditions for inclusion were a physician-diagnosed wheeze on auscultation and normal spirometric tests at rest on at least three occasions. Evaluation included skin prick tests for atopy and a physiciancompleted questionnaire. In addition, two tests of bronchial hyperresponsiveness (BHR) were performed - namely, exerciseinduced bronchospasm and inhaled methacholine hyperresponsiveness - as well as diurnal variability of peak expiratory flow (PV).

Results - One or more tests of BHR/PV were positive in $27(69 \%)$ but repeatedly negative in 12 (31\%). In terms of frequency of wheezing attacks, atopy, and questionnaire responses, there were no differences between BHR/PV and non-BHR/PV children, with the exception of a history of chest radiography proven pneumonia (only noted in the BHR/PV group). Overall, evidence of atopy (mainly indoor allergens) was noted in $21(56 \%)$ of those tested and parental smoking in $29(74 \%)$ of households. Thirty-two $(82 \%)$ of the children complained of an exercise-related wheeze, yet exercise-induced bronchospasm was only demonstrated in nine $(23 \%)$.

Conclusions - This selected group of wheezy children appears to be intermediate between a normal and clearly asthmatic population and, despite the recurrent wheezy attacks, some should probably not be classified as asthmatic by conventional criteria. Important aetiological factors in the symptomatology of these children may include parental smoking and atopy as well as other elements such as viral infections.

(Thorax 1996;51:272-276)

Keywords: wheeze, bronchial hyperresponsiveness, atopy, passive smoking.
A large number of children may present repeatedly with a history of wheezing. In practice, children with occasional wheezing are often promptly classified as asthmatics with implications both to the individual and in terms of the quality of the epidemiological data used to establish the true prevalence of asthma. Asthma awareness is increasing, and concurrently a disproportionate increase in wheezing illness is being reported. ${ }^{12}$ The prevalence of hayfever and eczema has increased substantially. ${ }^{34}$ Additionally, the role of house dust and other domestic allergens in the induction of asthma in children has recently been re-emphasised. ${ }^{5}$ Although the definition of asthma remains somewhat controversial, a low forced expiratory volume in one second $\left(\mathrm{FEV}_{1}\right)$ in the presence of a history of recurrent wheeze is consistent with asthma, especially if a reversible component can be demonstrated. Atopy and wheeze are associated with a reduced $\mathrm{FEV}_{1}{ }^{6}{ }^{6}$

In the presence of normal spirometric parameters various provocation tests, including a $10 \%$ or more reduction in $\mathrm{FEV}_{1}$ after exercise and methacholine inhalation challenge, as well as non-provoked spontaneous diurnal peak expiratory flow variability, are considered to be helpful in the diagnosis. Methacholine and histamine inhalation challenge tests have been used to screen populations for asthma but are thought to be somewhat oversensitive as a diagnostic tool in the asymptomatic population. In addition, variability in peak expiratory flow (which reflects spontaneous variations in airway calibre) not accompanied by any increase in methacholine responsiveness has been noted in the presence of respiratory symptoms. ${ }^{6}$ It has recently been suggested that asthma may be better defined as recent wheeze plus increased bronchial hyperresponsiveness (BHR). ${ }^{7}$

Some children wheeze from time to time in the presence of repeatedly normal spirometric values at rest. These children pose a clinical dilemma, frequently resulting in unnecessary diagnostic labelling and treatment. We hypothesised that if these children were really asthmatic, it would be appropriate to investigate some of the main aetiological factors known to be important in inducing asthma in this seemingly homogeneous population of wheezy children.

\section{Methods}

The population studied was aged between six and 16 years and referred by a specialist paediatrician working in a community clinic 
following a finding of wheezing on auscultation. The set-up of the services in that area is such that the clinic provides primary health care for a low socioeconomic urban population. The children who were referred from the community were subsequently studied at the Chaim Sheba Medical Center and had had 1-12 wheezing attacks a year over a two year period.

Additional conditions for referral were: (1) normal spirometric values at rest on at least three occasions over a two month period; (2) no hospital admissions during the previous three years; (3) no evidence of recent respiratory tract infection; and (4) no history of regular prophylactic asthma therapy. They were excluded if there was a history of cardiac or neuromuscular disorders or there were chest wall deformities. All subjects and parents were informed of the nature of the study before consenting to participate.

LUNG FUNCTION AND BRONCHIAL HYPERRESPONSIVENESS

Recordings of $\mathrm{FEV}_{1}$ and FVC (forced vital capacity) were made with a dry bellows spirometer (Vitalograph, Buckingham, UK) taking the highest of the first three successive measurements within $5 \%$ of each other. Spirometric tests were only considered normal if the values

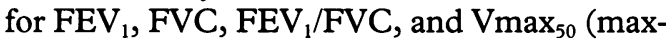
imal expiratory flow measured from the volume-time curve at $50 \%$ of vital capacity) were within normal limits for the Israeli population. ${ }^{8}$ Inhalation tests were performed with methacholine chloride using the Cockcroft protocol. ${ }^{9}$ The solutions were inhaled via a face mask in increasing doubling concentrations from $0 \cdot 125$ to $16 \mathrm{mg} / \mathrm{ml}$ by aerosol. The nebuliser had an output of $0.25 \mathrm{ml} / \mathrm{min}$ at an airflow rate of $5 \mathrm{l} / \mathrm{min}$. The subject was asked to breathe with a normal tidal volume for two minutes and consecutive doses were administered at five minute intervals. The $\mathrm{FEV}_{1}$ was measured at 30 and 90 seconds after each inhalation and the test was discontinued when the $\mathrm{FEV}_{1}$ had fallen by $20 \%$ or more. The provocative concentration of methacholine required to lower the $\mathrm{FEV}_{1}$ by $20 \%\left(\mathrm{PC}_{20}\right)$ was considered significant if it was $8 \mathrm{mg} / \mathrm{ml}$ or less. The test was repeated after six months in subjects with a $\mathrm{PC}_{20}$ of more than $8 \mathrm{mg} / \mathrm{ml}$ on the first occasion.

All exercise testing was performed in the same ambient conditions at the Respiratory Physiology Laboratory of the Chaim Sheba Medical Center. The exercise test involved running on a treadmill at an angle of 10 degrees at a speed of $8 \mathrm{~km} /$ hour for six minutes. A minimum pulse rate of 160 /minute was obtained in all subjects. Measurements of $\mathrm{FEV}_{1}$ were made before and at four, seven, and 10 minute intervals following the test. The exercise test was repeated in all subjects after three weeks.

All families were given a mini-Wright peak flow meter and children and parents were instructed as to its correct use. They were asked to record the highest of three daily morning and evening values over a three week period which were measured at approximately the same time every day. Peak expiratory flow (PEF) variability (PV) was considered significant if a diurnal variation (difference between maximum and minimum PEF measured on the same day as a percentage of the maximum PEF) of more than $15 \%$ was calculated on at least three days in addition to an absolute difference between the peak and trough PEF values of more than $20 \%$ over the three week period. Every effort was made to keep to the same order of investigations and this was achieved in most cases - namely, the methacholine inhalation challenge, exercise testing, three weeks of PEF measurements, followed by a repeat exercise test. The exercise test and methacholine inhalation challenge were never performed on the same day.

\section{ATOPIC STATUS}

Atopic status was assessed by a skin prick test with the following inhalant allergens: olive pollen, mixed grasses (June, timothy, orchard, rye), weeds (sagerbush, cocklebur, Bermuda, Russian thistle), house dust mite ( $D$ farinae), cockroach ( $B$ germanica whole body and faecal) (cockroach allergens kindly supplied by S B Lehrer, Tulane University, USA).

Histamine and saline were used as positive and negative controls. A skin prick test was considered positive if it showed a wheal size similar to or larger than the histamine control $(+3 \text { or larger wheal })^{10}$ and negative if there was no response or the same response as to the saline control. The mean wheal size in this group was $5.8 \mathrm{~mm}$ (coefficient of variation $22.5 \%$ ). A patient was considered atopic if one or more of the above tests was positive.

\section{QUESTIONNAIRE}

Details of the respiratory symptom history were obtained from both the subjects and parents by a physician-completed questionnaire. Questions were asked regarding a family history of asthma, number of wheezy attacks over past 12 months, nocturnal wheeze or cough, wheeze on exercise or rhinitis-associated wheeze, history of hayfever, eczema, vernal conjunctivitis as well as parental smoking. In addition, questions were asked about a history of well documented radiographically proven pneumonia.

\section{DATA ANALYSIS}

Correlation between each clinical parameter and the presence of BHR/PV was performed using the $\chi^{2}$ test or Fisher's exact method for categorical variables and ANOVA for continuous variables. A logistic regression model was employed using $\mathrm{BHR} / \mathrm{PV}$ as a dependent variable and clinical parameters as independent variables in order to determine the predicting factor (odds ratio) for the presence of BHR/ PV. Statistical analysis was performed by STATVIEW package (Abacus Concepts, Berkeley, USA) and BMDP statistical software (Los Angeles, USA). All reported $p$ values are two tailed and a $p$ value of less than 0.05 was considered positive. 
Table 1 Criteria for bronchial hyperresponsiveness (BHR/PV) in wheezing children $(n=39)$

\begin{tabular}{lll}
\hline Test & No positive & $\%$ Positive \\
\hline Methacholine & 20 & $51 \cdot 2$ \\
PEF diurnal variability (PV) & 15 & $38 \cdot 4$ \\
Exercise & 9 & $23 \cdot 0$ \\
BHR/PV* & 27 & $69 \cdot 2$ \\
\hline
\end{tabular}

* One or more positive tests.

Table 2 Mean (SE) demographics and frequency of wheezing in BHR/PV and non-BHR/PV children

\begin{tabular}{lccc}
\hline & $\begin{array}{c}\text { BHR/PV } \\
(n=27)\end{array}$ & $\begin{array}{c}\text { Non-BHR/PV } \\
(n=12)\end{array}$ & $\begin{array}{l}\text { Overall } \\
(n=39)\end{array}$ \\
\hline Male/female & $8 / 19$ & $6 / 6$ & $14 / 25$ \\
Age (years) & $10 \cdot 8(0 \cdot 5)$ & $11 \cdot 3(0 \cdot 7)$ & $10 \cdot 9(0 \cdot 4)$ \\
Attacks/year & $3 \cdot 4(0 \cdot 6)$ & $2 \cdot 5(0 \cdot 8)$ & $3 \cdot 1(0 \cdot 4)$ \\
\hline
\end{tabular}

\section{Results}

Fifty four children were referred for assessment, six of whom were excluded because of a subsequent finding of obstruction during spirometric testing at rest. Before initiation of the study five were deemed non-compliant and in four a repeat history was unsatisfactory. Thirty nine children met all of the above criteria and all completed the full evaluation with the exception of two subjects who declined skin prick testing.

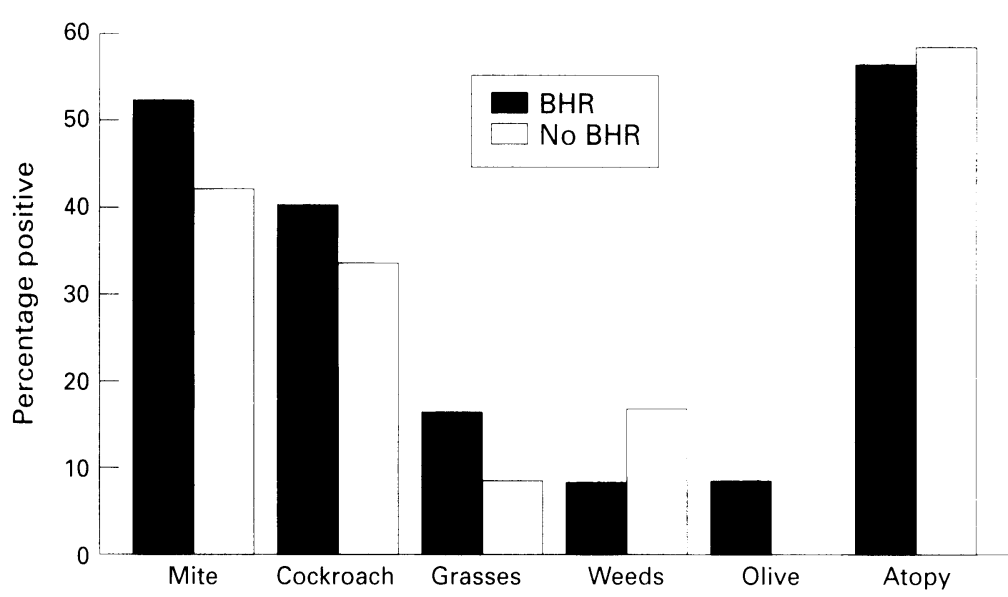

Figure 1 Skin test results in both BHR/PV and non-BHR/PV subjects: overall atopy and response to individual allergen extracts. BHR=bronchial hyperresponsiveness.

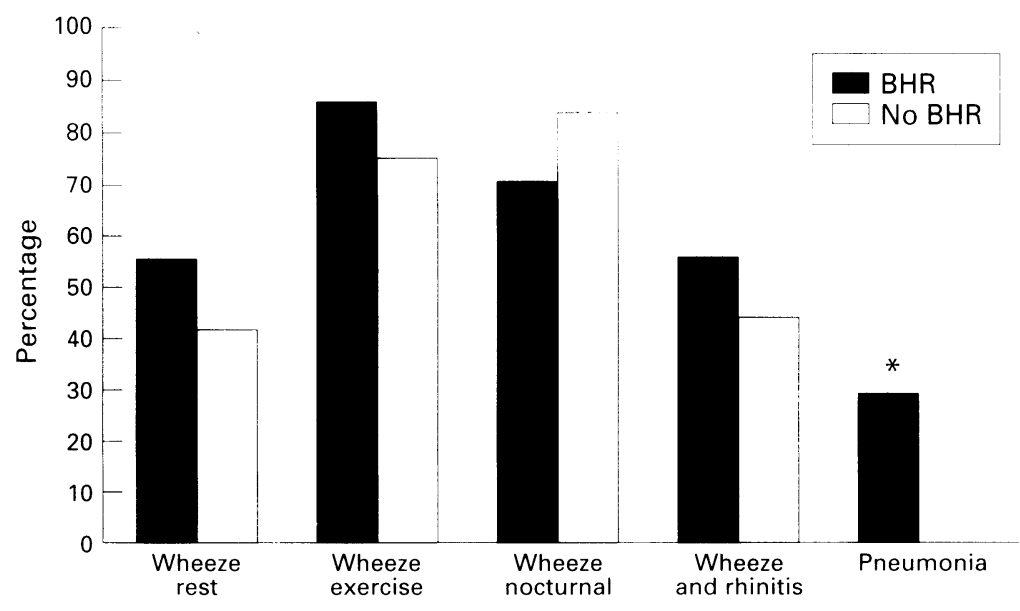

Figure 2 Results of questionnaire in both $B H R / P V$ and non-BHR/PV subjects (relating to details of past medical history). BHR=bronchial hyperresponsiveness. $* p<0 \cdot 05$.
$\mathrm{BHR} / \mathrm{PV}$ was defined as a positive result in one or more of the three tests (methacholine inhalation, PEF variability, and exercise-induced bronchospasm) and was noted in 27 patients. Overlap was clearly present in these 27 children with $\mathrm{BHR} / \mathrm{PV}$, with a significant $\mathrm{PC}_{20}$ to methacholine in $20(74 \%)$, PEF variability (PV) in $15(55.6 \%)$, and exercise-induced bronchospasm in nine $(33.4 \%)$. The breakdown of $\mathrm{BHR} / \mathrm{PV}$ in the whole population of wheezy children is as shown in table 1. In five children PV was clearly present despite no evidence of BHR by other methods when tested at the same time. All tests for BHR/PV were negative in 12 and in no case did the repeated methacholine inhalation challenge or exercise test result in a change in classification from non-BHR/PV to BHR/PV. We did not repeat methacholine inhalation challenge in the positive children. Table 2 gives the male/female ratio, mean age, as well as the mean number of attacks per year. Figure 1 shows the percentage of positive skin tests in children from both groups. Of the 37 subjects who were skin tested $21(57 \%)$ were atopic, and most of these atopic children responded to dust mite (18, $86 \%)$ and cockroach $(13,67 \%)$ allergen extracts. There were no statistically significant differences in the presence or absence of atopy between the BHR/PV and non-BHR/PV groups.

Figure 2 gives the results of questionnaire responses. There were no statistically significant differences between the groups except for a history of radiographically proven pneumonia ( $p<0.05$, Fisher's exact method). This parameter has been shown to be predictive for $\mathrm{BHR} / \mathrm{PV}$ (odds radio $11 \cdot 5, \mathrm{p}<0 \cdot 05$, confidence interval 90\%).

No other anamnestic or clinical factor could predict the development of BHR/PV in this group of wheezy children. Symptoms of wheeze on exercise and nocturnal wheeze were common and were noted in $32(82 \%)$ and 29 (74\%), respectively.

At least one parent smoked in $29(74 \%)$ of the households, but in 18 only the father smoked. Eleven $(28 \%)$ of the mothers smoked during pregnancy. Figure 3 refers to a history of past atopic disease, asthma in the family, and parental and maternal smoking. There were no statistically significant differences between the groups.

\section{Discussion}

We decided to base the study of this carefully selected well characterised group of children on physician-diagnosed wheeze as many of the recent reports of asthma in children are based on reporting by a patient or parent. In one study $74 \%$ of non-atopic wheezy children with no evidence of histamine BHR were classified as asthmatic and $21 \%$ were receiving medication. $^{7}$ Despite the fact that a universally acceptable definition of asthma remains elusive, much has been learned about atopy and BHR in a clearcut asthmatic population of children. Testing for BHR is intended to diagnose both provoked and spontaneous variations in airway 


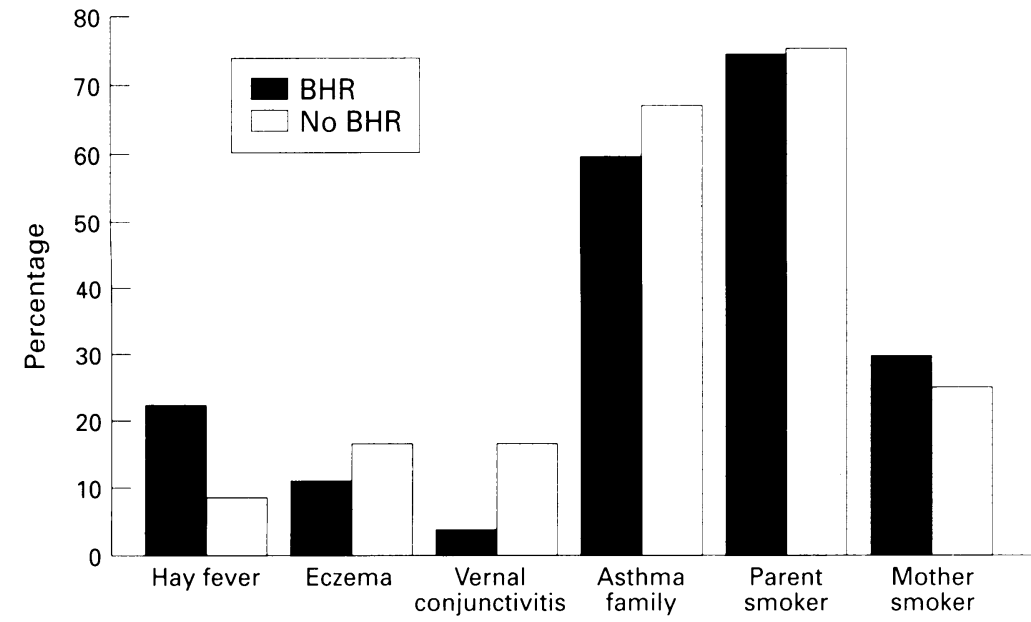

Figure 3 Results of questionnaire in both BHR/PV and non-BHR/PV subjects (relating to details of past medical history, particularly atopy, family history of asthma, and smoking). BHR=bronchial hyperresponsiveness. calibre, and therefore we decided to investigate three indices of lung function variability with two provocation methods (methacholine and exercise) and spontaneous variation (diurnal peak flow measurements). Atopy was present in $80-90 \%$ of childhood asthmatics. ${ }^{67911}$ Histamine or methacholine BHR has been noted in $66-85 \%,{ }^{71213}$ PEF variability in $60-72 \%,{ }^{1+}$ and exercise-induced bronchospasm in up to $89 \%$ of asthmatic children ${ }^{15}$ but is probably lower in milder asthma. ${ }^{16}$ Our local experience is consistent with the published data from various regions of the world. It has been shown that respiratory tract symptoms may be accompanied by changes in PEF without demonstrable methacholine BHR. ${ }^{6}$ Furthermore, clinical evaluation of children with mild occasional wheezing reveals that they frequently complain of wheezing on exercise and this was borne out by the results of our physician-completed questionnaire. It therefore seemed appropriate to include PEF variability as well as exercise testing in our evaluation.

It is likely that, with three different tests intended to evaluate spontaneous and provoked variations in airway calibre, which were repeated after six months, that $\mathrm{BHR} / \mathrm{PV}$ was effectively excluded in 12 of the wheezy children. Atopy in the general paediatric population is between $25 \%$ and $35 \%,{ }^{717}$ yet $56 \%$ of our wheezy children were atopic, regardless of the presence of BHR/PV. Reactions to domestic allergens such as house dust mite and cockroaches were detected in most of the atopic subjects. The majority of this population does not keep household pets and we therefore did not skin test for these allergens.

The children were recruited from a single community paediatric clinic serving a low socioeconomic population similar to that in the study by Gelber et al. ${ }^{18}$ Similarly, in our study $38 \%$ had positive skin tests to cockroach allergen (either whole body extract, faecal, or both).

It has been suggested that, for epidemiological purposes, current wheeze and BHR is consistent with a diagnosis of asthma ${ }^{7}$ and, based on these criteria, $27(69 \%)$ of our
39 subjects could be diagnosed as asthmatic. In addition, despite repeated testing, overall exercise-induced bronchospasm was only detected in nine $(23 \%)$ and, even in the BHR PV group, in only nine of $27(33 \%)$ which is considerably less than one would expect from an asthmatic population. It was remarkable that as many as $82 \%$ of the children in both the BHR/PV and non-BHR/PV groups had complained of wheezing on exercise. All of the children with a history of radiographically proven pneumonia had evidence of BHR/PV (eight of 39). Wheeze has been associated with low values of $\mathrm{FEV}_{1}{ }^{6}$ and $\mathrm{FEV}_{1} / \mathrm{VC}^{19}$ and atopy with a reduced $\mathrm{FEV}_{1} / \mathrm{VC}^{20}{ }^{20}$ Our very carefully selected group of subjects had repeatedly nor-

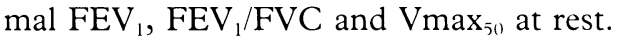

It must be noted that the sample size of this group was not predetermined by power based calculations, but rather was dependent on the number of children that could be recruited from a specific neighbourhood. They appeared to be homogeneous in terms of their symptomatology, physical and physiological findings, as well as area of residence. Careful scrutiny of the information, as shown in figs $1-3$, points to many similarities between the groups.

More than half of our group were sensitive to domestic allergens and, in addition, parental smoking - which could be a significant contributory factor ${ }^{1+}$ - was reported in three quarters of the households. This compares with a prevalence of $24-39 \%$ of smoking in the general Israeli population. ${ }^{21}$ Eleven $(28 \%)$ of the mothers smoked (during and after pregnancy). However, if the fathers were considered, one or more parent smoked in $29(74 \%)$ of households. As we were studying a low socioeconomic population with a high unemployment rate, it may be relevant that fathers spend more time at home than in other social groups. In addition, the role of viral respiratory tract infections, particularly rhinovirus, needs to be further investigated in these children as they may be an important trigger of symptoms. ${ }^{223}$

We conclude that some children with occasional wheeze may not be asthmatic by conventional criteria. It is likely that various factors may be responsible for the symptomatology in certain "susceptible population groups".

We acknowledge the support of the Israel Lung Association and of Trupharm, Netanya, Israel and thank Vitalograph, Buckingham, UK who supplied some of the equipment used in the ingham, UK who supplied some of the equipment used in the
study. We would also like to thank Ms Angela Shitrit (Gertner study. We would also like to thank Ms Angela Shitrit (Gertner
Institute, Tel-Hashomer) for her dedicated assistance with the statistical analysis.

1 Strachan DP, Anderson HR. Trends in hospital admission rates for asthma in children. BM7 1992;304:819-20.

2 Hill R, Williams J, Tattersfield A, Britton J. Change in the use of asthma as a diagnostic label for wheezing illness in schoolchildren. BMF 1989;299:898.

3 Burr ML, Butland BK, King S, Vaughan-Williams E. Changes in asthma prevalence: two surveys 15 years apart. Arch Dis Child 1989;64:1452-6.

4 Ninan TK, Russel D, Russell G. Increasing prevalence of respiratory symptoms and atopy in Aberdeen schoolchildren: evidence from two surveys. BMF 1992;304:873 5 .

5 Sporik R, Holgate ST, Platts-Millis TAE, Cogswell JJ. Exposure to house-dust mite allergen $\left(D_{e} r \quad p \quad I\right)$ and the development of asthma in children. N Engl F Med 1990; 323:502-7.

6 Clough JB, Williams JD, Holgate ST. Effects of atopy on the natural history of symptoms, peak expiratory flow and bronchial responsiveness in 7 - and 8 -year old children 
with cough and wheeze. Am Rev Respir Dis 1991;143: 755-60.

7 Toelle BG, Peat JK, Salome CM, Woolcock AJ. Toward a definition of asthma for epidemiology. Am Rev Respir Dis 1992;146:633-7.

8 Roizin H, Szeinberg A, Tabachnick E, Molho M, Benzaray $S$, Augarten A, Har-Even D, Barzilay Z, Yahav J. Ethnic differences in lung function in Israeli children. Thorax 1993;48:906-10.

9 Cockroft DW, Killian DN, Mellon JJ, Hargreave FE. Bronchial reactivity to inhaled histamine: a method and clinical survey. Clin Allergy 1977; 7:235-43.

10 Bousquet J, Michel FB. In vivo methods for study of allergy skin tests, techniques and interpretation. In: Middleton E, Reed CE, Ellis EF, Adkinson NF, Yuninge JW, Busse WW, eds. Allergy, principles and practice. St Louis: MosbyYear Book, 1993: 573-94

11 Clifford RD, Radford M, Howell JB, Holgate ST. Prevalence of atopy and range of bronchial response in 7 and 11 year-old school children. Arch Dis Child 1989;64:1126-32.

12 Hopp RJ, Bewtra AK, Nair NM, Watt GD, Townley RG Methacholine inhalation challenge studies in a selected pediatric population. Am Rev Respir Dis 1986;134:994-8.

13 Salome CM, Peat JK, Britton WJ, Woolcock AJ. Bronchial hyperresponsiveness in two populations of Australia schoolchildren. 1. Relation to respiratory symptoms and diagnosed asthma. Clin Allergy 1987;17:271-82.

14 Lebowitz MD, Sherrill D, Holberg CJ. Effects of passive smoking on lung growth in children. Pediatr Pulmonol 1992;12:37-42.
15 Anderson SD, Silverman M, Konig P, Godfrey S. Exerciseinduced asthma. Br $\mathcal{F}$ Dis Chest 1975;69:1-39.

16 Godfrey S, Bar-Yishay E. Exercise-induced asthma revisited. Respir Med 1993:87:331 Exercise

17 Godfrey RC, Griffiths M. The prevalence of immediate positive skin tests to $D$ pteronyssinus and grass pollen in schoolchildren. Clin Allergy 1976;6:79-82.

18 Gelber LE, Sletzer LH, Bouzoukis JK, Pollart SM, Chapman MD, Platts-Mills TAE. Sensitisation and exposure to indoor allergens as risk factors for asthma among patients presenting to hospital. Am Rev Respir Dis 1993; 147:573-8.

19 Sherrill D, Holberg CJ, Lebowitz MD. Differential rates of lung growth as measured longitudinally by pulmonary function in children and adolescents. Pediatr Pulmonol 1990;8:145-54

20 Sherrill D, Sears MR, Lebowitz MD, Holdaway MD, Hewitt CJ, Flannery EM, et al. The effects of airway hyperresponsiveness, wheezing and atopy on longitudinal pulmonary function in children: a 6-year follow-up study. Pediatr Pulmonol 1992;13:78-85.

21 Department of Health Education. Smoking prevalence in Israel. Israel Ministry of Health Report, 1994.

22 Johnston SL, Sanderson G, Pattemore PK, Smith S, Bardin PG, Bruce CB, et al. Use of polymerase chain reaction for diagnosis of picornavirus infection in subjects with and without respiratory symptoms. F Clin Microbiol 1993;31: 111-7.

23 Dodge R, Burrows B, Lebowitz MD, Cline MG. Antecedent features of children in whom asthma develops during the second decade of life. F Allergy Clin Immunol 1993;92. 744-9. 